\title{
Banco de Sangre de Cordón Umbilical del Centro Nacional de la Transfusión Sanguínea: una retrospectiva
}

\author{
Julieta Rojo-Medina* y José Luis Salazar-Bailón \\ Centro Nacional de Transfusión Sanguínea (CNTS), Ciudad de México, México
}

\section{INTRODUCCIÓN}

Se expone la relevancia del Banco de Sangre de Cordón Umbilical (BSCU) del Centro Nacional de la Transfusión Sanguínea (CNTS) como uno de los pilares en la obtención de concentrados de células progenitoras hematopoyéticas $(\mathrm{CPH})$ en sangre placentaria.

Nuestro antecedente data de 1974, cuando se logró demostrar que la sangre placentaria es rica en $\mathrm{CPH}$; se obtiene mediante una punción en el cordón umbilical justo después del nacimiento del producto. Esto supuso una revolución en el campo de la hematología, ya que se verificó la movilización natural de estas células, y se evidenció clínicamente su capacidad de injerto in vitro y su capacidad de reconstituir de forma integral el sistema hematopoyético de un individuo.

Fue en 1988 cuando Elaine Gluckman realizó el primer trasplante de regeneración de médula ósea con células obtenidas de sangre placentaria. A partir de esa fecha, se ha incrementado paulatina y sostenidamente, en México y en el mundo, la utilización de las CPH obtenidas de sangre de cordón umbilical para regeneración de la médula ósea, en el tratamiento de padecimientos hematológicos, oncológicos, inmunológicos y algunas enfermedades genéticas

Con el paso de los años, los bancos de SCU desarrollaron una cada vez más amplia diversidad en la metodología

empleada, por lo que los esfuerzos de estandarización de procesos se han intensificado con la intención de homogeneizar criterios y mejorar la calidad de los productos. Uno de los grupos que ha trabajado de forma más apropiada y que ha elaborado estándares que contemplan regulaciones nacionales e internacionales es la Foundation for the Accreditation of Hematopoietic Cell Therapy.

\section{BANCO DE SANGRE DE CORDÓN UMBILICAL}

En México, el CNTS inició las actividades del BSCU en el año 2003 y su objetivo es la colecta, criopreservación y liberación de unidades de sangre de cordón umbilical que cumplan con los estándares internacionales de calidad, para el trasplante alogénico de médula ósea, en pacientes atendidos en instituciones del Sistema Nacional de Salud que lo requieran. Para lograrlo, orienta sus actividades con las siguientes premisas fundamentales:

- Donación altruista de sangre de cordón umbilical.

- Confidencialidad.

- Calidad.

- Criterios estrictos de selección. 
El BSCU es una estructura multidisciplinaria, responsable de la promoción de la donación, lo cual incluye la difusión de las ventajas de la donación voluntaria y altruista de la sangre de cordón umbilical sobre la preservación autóloga, el reclutamiento y fidelización de las madres donantes, así como de la recepción, procesamiento, análisis, criopreservación, registro, escrutinio de calidad precriopreservación, búsqueda de unidades compatibles y, en su caso, la reserva, validación, control de calidad pretrasplante, así como la distribución del producto para su infusión.

Al ser un una entidad pública sin ánimo de lucro y que gestiona solamente unidades obtenidas por donación voluntaria y altruista, las unidades son almacenadas sin ningún costo para la donante. Del total de donaciones $(6,066)$, se han logrado validar 1,994 unidades; por tanto, el acervo actual del BSCU al cierre de 2018 es de 1,450 unidades, fomentando y asegurando su calidad, seguridad y eficiencia. Del total de las unidades aceptadas para criopreservación, se han enviado 373 con fines de trasplante y 125 han sido empleadas con fines de investigación y control de calidad.

Los diagnósticos por los cuales se han liberado las unidades para trasplante de regeneración de médula ósea fueron, por orden de frecuencia: las leucemias (73\%), la anemia aplásica (11.5\%) y otros diagnósticos, entre ellos, errores innatos del metabolismo y enfermedades raras (13\%), linfomas (2.5\%) y, por último, las inmunodeficiencias (2\%).

Las instituciones de salud que las recibieron se muestran en la tabla 1.

Al basar sus procesos en tecnología automatizada y en estándares internacionales, el BSCU se convirtió en miembro asociado de NETCORD (2006), siendo en ese entonces el único banco de cordón de Latinoamérica en formar parte de esta red internacional. Seguir dichos estándares permitió optimizar los procesos y adaptarlos a criterios internacionalmente aceptados de acuerdo con prácticas de buena manufactura, de forma que se convirtió en un centro de búsqueda de unidades compatibles de muchas instituciones en Latinoamérica.

\section{SITUACIÓN ACTUAL}

Mundialmente, los bancos de sangre se enfrentan esencialmente a tres grandes retos: la regulación sanitaria, los
Tabla 1. Instituciones del Sistema Nacional de Salud que han recibido unidades de células progenitoras hematopoyéticas del CNTS*

\begin{tabular}{lcc}
\hline Institución & Unidades & $\%$ \\
\hline Institutos Nacionales de Salud & 168 & 50.6 \\
Secretaría de Salud & 70 & 21.1 \\
Seguridad Social & 52 & 15.7 \\
Privadas & 36 & 10.8 \\
PEMEX & 4 & 1.2 \\
ISSSFAM & 2 & 0.6 \\
TOTAL & 332 & 100.0 \\
\hline
\end{tabular}

*Se han enviado, además, 37 unidades al Instituto SOLCA en Ecuador, 2 al Centro Médico Imbanaco de Cali, Colombia, y 2 al Hospital Pablo Tobón Uribe en Medellín, Colombia. CNTS: Centro Nacional de la Transfusión Sanguínea; ISSSFAM: Instituto de Seguridad Social para las Fuerzas Armadas; PEMEX: Petróleos Mexicanos.

estrictos criterios de calidad y el bajo porcentaje de uso. Respecto a la regulación sanitaria, México cuenta con el Proyecto de Norma Oficial Mexicana 260-SSA1-2017 «Para la disposición de células troncales y progenitoras con fines terapéuticos y de investigación», que proveerá al país de un marco normativo con estándares internacionales que garanticen la calidad y seguridad en cuanto a la obtención, evaluación, procesamiento, almacenamiento y disposición de estas unidades. Además, ayudará a evitar el uso indiscriminado de estas células y evitará publicidad engañosa con la que ciertos establecimientos han promovido el empleo de este recurso.

En cuanto al uso del servicio del BSCU en la última década, con el desarrollo y generalización de los trasplantes haploidénticos, que supuso la realización del trasplante con células obtenidas de la movilización y obtención de sangre periférica o de la médula ósea, se fueron empleando cada vez menos unidades de cordón umbilical. Si bien se obtuvo un crecimiento del inventario del banco, este se ha enfrentado a una disminución proporcional del total de unidades trasplantadas por cada banco público, lo que a nivel global planteó dudas sobre su sustentabilidad. Estimaciones basadas en la existencia total de unidades criopreservadas en todo el mundo señalan que solo una de cada 10 unidades recolectadas se utiliza para fines de trasplante.

No obstante, los reportes actuales muestran que en los últimos dos años ha habido un incremento sostenido en el número de trasplantes con células de cordón umbilical, ya que el costo global del trasplante haploidéntico, o incluso del alogénico de donante no relacionado, han sido muy superiores al costo del proceso global de una 
unidad de sangre placentaria, por lo que muchos centros han redirigido sus esfuerzos a la optimización del trasplante con este tipo de fuente.

\section{CONCLUSIÓN}

Desde los albores del trasplante de regeneración hematopoyética en México, el BSCU del CNTS ha evolucionado considerablemente y ha contribuido al tratamiento exitoso de una gran cantidad de pacientes con una gran variedad de padecimientos hematológicos, alcanzando el injerto hematopoyético y la supervivencia a la experiencia internacional; además, ha contribuido con unidades para investigación. Sin embargo, el BSCU asume y enfrenta los retos continuos de la disciplina: mejorar la cuenta de células CD34+ por unidad, mejorar la compatibilidad en el sistema antígenos leucocitarios humanos (HLA) y proveer de unidades seguras y eficaces para coadyuvar con los centros de trasplante en mejorar el pronóstico de los pacientes que requieren este tratamiento. 